\title{
Attitude of medical functionaries towards the need of nutritional knowledge of nurses in selected hospitals of Assam, India
}

\author{
PALLAVI TALUKDAR, JULIANA SARMAH AND MANJU DUTTA
}

Received: 04.04.2017; Revised: 26.04.2017; Accepted: 13.05.2017

See end of the paper for authors' affiliations PALLAVI TALUKDAR Department of Extension Education, College of Home Science, Assam Agricultural University, JORHAT (ASSAM) INDIA

Email : nimitalukdar@yahoo.co. in
ABSTRACT : Nutritional knowledge and attitudes of medical functionaries from government and private hospitals in selected district of Assam, India was studied. About 90 per cent of practicing nurses had favorable attitudes toward nutrition. Age of the nurses exhibited positive influence towards the nutritional knowledge, while general educational qualification and mass media exposure had no significant correlation with the attitudes. Relationship between the nutritional knowledge of respondents with their opinion towards the need of their nutritional knowledge revealed that there was highly and positive significant correlation between nutritional knowledge of the respondents with their opinion towards the need of nutritional knowledge of nurses. Knowledgeable nurses had more positive attitudes toward their own role in nutrition education and toward the team approach to health care.

KEY WORDS: Nutritional knowledge

- HOW TO CITE THIS PAPER : Talukdar, Pallavi, Sarmah, Juliana and Dutta, Manju (2017). Attitude of medical functionaries towards the need of nutritional knowledge of nurses in selected hospitals of Assam, India. Asian J. Home Sci., 12 (1) : 222-225, DOI: 10.15740/HAS/AJHS/12.1/222-225. 